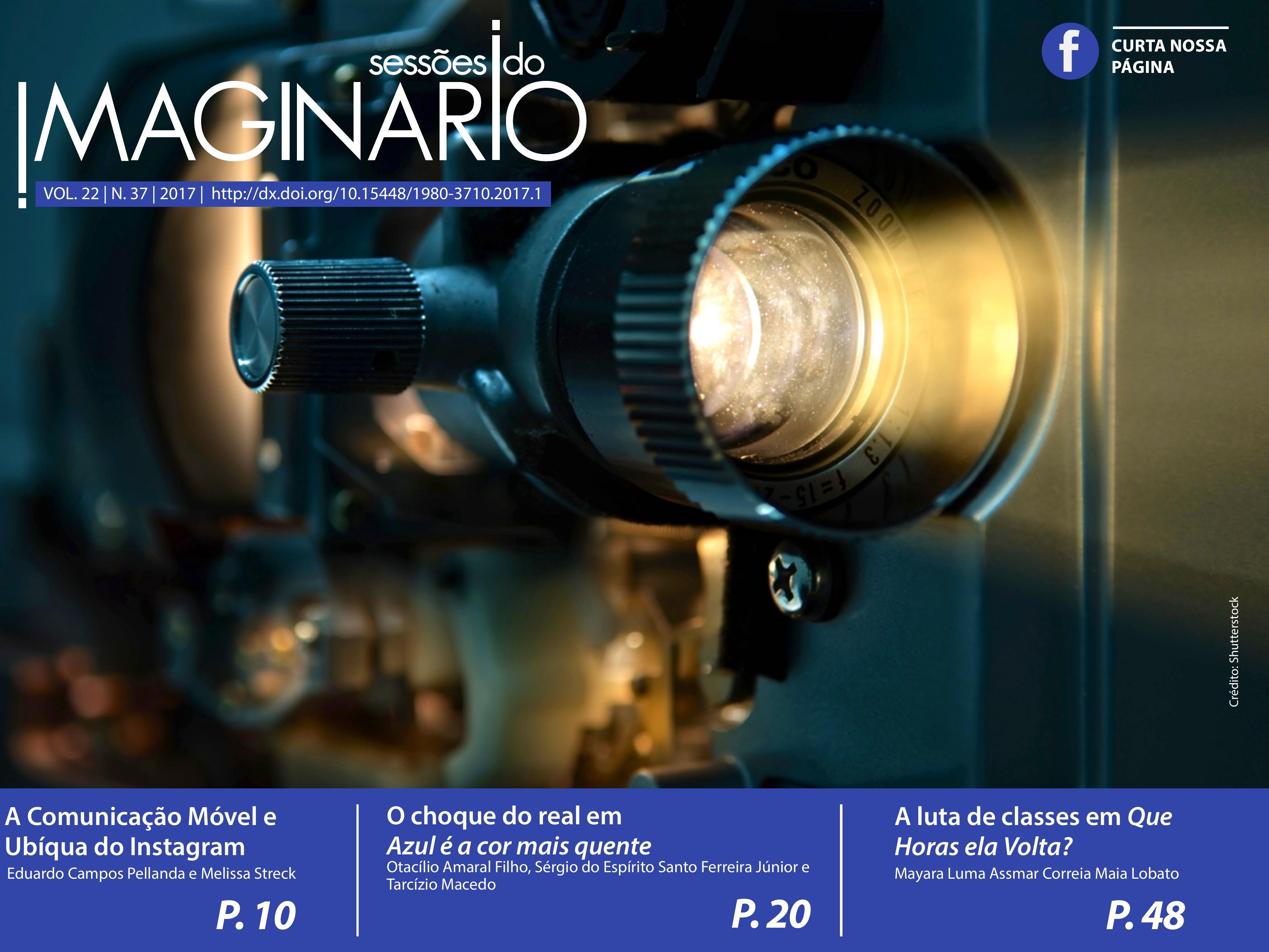




\section{Instagram como Interface da Comunicação Móvel e Ubíqua $^{1}$}

Instagram as the Mobile and Ubiquitous Communication Interface

Eduardo Campos Pellanda ${ }^{1} \boldsymbol{J}$ Melissa Streck $\left.{ }^{2}\right]$

\section{AUTOR CONVIDADO}

\section{Resumo}

O presente artigo tem como objetivo analisar a rede Instagram como um objeto de análise para categorias da comunicação móvel. Esta rede social digital disponibiliza diferentes ferramentasparaaediçãodasimagens nela publicadas, além de recursos como marcação de pessoas e locais, permitindo inclusive o agrupamento de fotos por contextos. Usuários são levados a expor suas experiências de determinado local e contexto, através de seu ponto de vista. Por sua vez, os usuários seguidores verão a imagem através de suas experiências e principalmente pelo contexto possibilitado pelos filtros e edições disponíveis na própria interface gráfica do Instagram.

\section{Palavras-chave}

Instagram; fotografia; ubiquidade; mobilidade; presença.

\section{Abstract}

This article aims to analyze the Instagram network as an object of analysis for categories of mobile communication. This digital social network offers different tools for editing the images published in it, as well as resources such as marking people and places, allowing even the grouping of photos by contexts. Users are led to expose their experiences of given place and context, from their point of view. In turn, the followers users will see the image through their experiences and mainly by the context made possible by the filters and editions available in the graphical interface of Instagram.

\section{Keywords}

Instagram; photography; ubiquity; mobility; presence.

10 PORTO ALEGRE | v. 22 | n. 37| 2017 | pp. 10-19 DOl: http://dx.doi.org /10.15448/1980-3710.2017.1.28017 Sessões do Imaginário 


\section{Introdução}

A comunicação através de dispositivos móveis conectados à internet atingiu no ano de 2016 graus de difusão extremos, com países como Índia e China tendo um bilhão de usuários cada ${ }^{4} \mathrm{e}$ com a previsão de 5 biIhões de usuários em nível global para o ano de 20195, que se aproxima. Devido ao uso intenso, o estudo das características deste tipo interação torna-se urgente, tanto pelo consumo de aparelhos quanto pelo uso de aplicativos. Desde os primeiros esboços das investigações do campo, realizados por pesquisadores como Eduardo Pellanda (2005) ou André Lemos (2009), procura-se por uma relação que estabeleça uma busca por objetos relevantes que possam evidenciar as peculiaridades da internet onde os "nós" da rede se deslocam. Destacam-se também para este campo os estudos de Howard Rheingold (2003) e sua busca pela resultante cinética que influencia a mensagem, além dos estudos fundamentais de Lev Manovich (2011) sobre a ferramenta Instagram e os comportamentos de seus usuários.

Neste contexto, a rede social digital Instagram é um objeto que se aproxima da perfeição para evidenciar tal forma de comunicação móvel, principalmente através da imagem. O Instagram ${ }^{6}$ é um aplicativo de rede social digital destinado à publicação de imagens obtidas através de um smartphone que são tratadas, ou seja, permitem que o usuário execute algumas edições para melhoria da imagem antes de sua publicação. A ideia desta rede é que as fotos sejam instantâneas, publicadas instantes após a captura da imagem original. Tanto isto é verdade que o ícone do Instagram ${ }^{7}$ remetia inicialmente a uma máquina fotográfica do estilo Polaroid, câmera que teve seu glamour e fama justamente pelo fato de revelar as fotos quase que instantaneamente à captura.
Este artigo trata do uso pessoal do aplicativo, desconsiderando questões do uso comercial que muitas empresas fazem do mesmo. Desta forma, qualquer indivíduo, desde que provido de tal ferramenta para tirar e publicar fotos ou vídeos, pode compartilhar e interagir sobre uma memória de algum lugar que visitou ou de alguma situação que vivenciou por um período maior de tempo. Uma foto publicada em uma rede social se mantém permanente, desde que não seja apagada ou tenha alguma alteração em suas configurações no perfil do usuário, como privacidade, por exemplo. Ou seja, ao publicar uma foto, o usuário tem consciência da rapidez com que outros usuários poderão interagir com sua publicação e do feedback que receberá. A cada nova interação de sua rede de contatos, estará o usuário e autor da publicação, mesmo que já em outro local ou em outra situação, voltando à memória do local ou da situação na qual postou sua foto. O contexto do local, no momento publicado, poderá remeter àquele mesmo local a qualquer instante em que houver interação na sua publicação.

Pretende-se então, neste artigo, traduzir a ideia de continuidade da memória através de uma situação que seria como que um "túnel midiático", em que o usuário percebe-se em um local e seu contexto, em seguida, ele publica uma imagem deste local em redes sociais e, por último, após ter saído do contexto do local e da foto, mantém aquela memória através da interação com outros usuários participantes em sua rede, olhando pelo ângulo dos recursos e funcionalidades da interface gráfica do usuário (GUI) oferecida pelo aplicativo Instagram. Para tanto, o artigo será dividido em duas etapas principais. A primeira que trata sobre mobilidade, retenção de momentos e instantaneidade de feedback através da ferramenta Instagram, trazendo um embasamento mais teórico e descritivo sobre o Instagram. A segunda parte trata mais especificamente dos elementos da interface gráfica do usuário como conectores dos espaços físicos e virtuais, comentando aspectos da ferramenta que permitem ao usuário fazer a transição entre local físico e sua permanência através de uma memória fotográfica e interação com outros usuários.

\section{Mobilidade, feedback e retenção de} momentos através do Instagram

Gilder observou, há quase duas décadas, que os telefones celulares de hoje permitem ao usuário cada vez mais poder e abrem um mundo de possibilidades, independentemente de onde estejam: "Em breve seu celular irá se mais poderoso do que seu computador pessoal convenciona. (...) Ele irá tirar fotos e projetar elas em uma parede ou tela, ou dispará-las para outro dispositivo ${ }^{8 \prime \prime}$ (Gilder, 2000, p. 83). Desde a invenção do telefone celular, a comunicação interpessoal e instantânea à distância passou a ganhar novo sentido. Não era mais preciso estar em determinado local para falar com outra pessoa, através do aparelho telefônico. A partir de então, pessoas, em qualquer lugar, onde houvesse sinal, podiam se conectar e, conforme Castells et al, criar novos espaços públicos (2007).

Com o surgimento dos smartphones, o comportamento dos usuários de câmeras fotográficas e de celulares foi fortemente afetado. Se antes as pessoas levavam o celular e a câmera fotográfica junto, ao saírem para um passeio ou para um evento, agora a câmera é levada dentro do celular e pode ser muito mais facilmente acessada. Lugares e objetos passam a ser alvo desta tecnologia, ou ainda, segundo Santaella, "os lugares e objetos passam a dialogar com dispositivos informacionais, enviando, coletando e processando da- 
dos a partir de uma relação estreita entre informação digital, localização e artefatos digitais móveis" (2008, p. 96). Ou ainda, conforme Lemos, novas mídias móveis digitais ampliam as possibilidades para os usuários consumidores, permitindo "produzir e distribuir informação, fazendo com que esta se exerça e ganhe força a partir da mobilidade física" (2009, p. 30).

É comum que smartphones populares possuam duas câmeras, uma frontal e uma traseira. A câmera frontal tem seu uso definido para as selfies, ou seja, fotos que o usuário tira de si mesmo. E a câmera traseira pode ser usada como as câmeras fotográficas de antigamente, porém com visualização e manuseio através da tela do celular. Pois bem, com esta ferramenta constantemente em mãos, as pessoas levam suas vidas, cada uma de seu jeito, podendo capturar momentos seus e compartilhando-os com terceiros. Manovich (2016) aponta o uso do Instagram, por toda uma nova geração, como ferramenta para esta personalização.

Quanto às selfies, Peraica (2017) elucida a questão de que a selfie contemporânea é diferente de uma foto tirada em outros tempos, pois agora ela possui autoria própria, enquanto que em outras épocas dependia de um terceiro que a fizesse. A pesquisadora ainda comenta que "Ainda tinham uma intenção de enviar uma mensagem visual para alguém não estiver presente, uma mensagem de lembrete no futuro. Quando visto pelo destinatário desejado, estas imagens podem evocar memórias ${ }^{9 \prime}$ (Peraica, 2017, p. 15). Tanto isto é fato, que uma ferramenta popular chamada "pau de selfie" é usada como uma extensão do braço para o usuário segurar um smartphone e posicionar a câmera em frente, de acordo com a posição desejada para que a foto seja feita. Outro ponto facilitado em relação a autoria própria da selfie, é a possibilidade de o autor escolher, dentre diversas capturas obtidas em um curto espaço de tempo, a imagem de si que mais gostou e que será publicada em sua rede social.

Voltando a uma questão mais técnica, as câmeras de celulares, bem como as fotos tiradas, podem ser integradas com aplicativos diversos, instalados pelos usuários em seus respectivos smartphones, independentemente do tipo de sistema utilizado. Um destes aplicativos é o Instagram, cuja plataforma foi criada para ser usada em celular ${ }^{10}$. Ou seja, é a primeira rede social online nativa de smartphones, sendo através dela que usuários podem publicar, ver, curtir e comentar fotos publicadas por seus amigos. Ao comentar fotos, pode usar emojis" e marcar amigos específicos no campo de texto. As hashtags $^{12}$, ou palavras-chave, também são bastante utilizadas no Instagram, facilitando o agrupamento de assuntos na rede social e em sites de busca.

$\mathrm{O}$ ato de publicar uma foto pode ser feito de duas maneiras: o usuário pode tirar uma foto através do aplicativo do Instagram; ou pode escolher uma foto já existente na biblioteca de imagens de seu aparelho celular. Feito isto, ele passa à edição de fotos, adicionando filtros e fazendo diversos ajustes de edição. Além de todas estas opções, o usuário pode optar por inserir bordas ou não, deixando a foto no estilo das fotos reveladas pelas Polaroides da década de 1970. São filtros que remontam técnicas anteriores e quando Manovich analisa os filtros do Photoshop ${ }^{13}$, constata:

Como esses filtros, muitas das "novas" técnicas de criação, edição e análise de mídia implementadas em aplicativos de software não foram desenvolvidas especificamente para trabalhar com dados de mídia. Em vez disso, eles foram criados para o processamento de sinal e informação em geral - e en- tão foram diretamente transferidos para, ou adaptados para trabalhar com mídia14 (2013, p. 133).

Ao final das edições, pode o usuário postar sua imagem para seus seguidores ou enviá-la para pessoas específicas, desde que também usuárias do aplicativo, permitindo uma interação praticamente imediata com seus seguidores no aplicativo. Sobre esta última questão, Santaella comenta que "[...] uma das características principais da tecnologia criada e distribuída em forma digital, potencializada pela configuração informacional em rede, é permitir que os meios de comunicação possam atingir os usuários e obter um feedback imediato" (2004, p. 151). Porém, mais adiante será abordada a questão da assíncrona, ou seja, o feedback poderá não ser tão imediato conforme aponta Santaella, mas também poderá vir a qualquer momento posterior à publicação.

$\mathrm{O}$ ato de publicar uma foto, bem como de editá-las da maneira como o usuário deseja, pode ser realizado a qualquer momento e em qualquer lugar, sendo a publicação somente possível quando houver conexão com a internet. Porém, este último fator é um problema cada vez mais raro nos grandes centros urbanos, devido à ubiquidade das conexões sem fio, além dos pacotes de conexão oferecidos por operadoras de celular. $\mathrm{Ou}$ seja, através das conexões, as pessoas encurtam distâncias e levam sua presença a diferentes lugares físicos. Como comenta Castells (2003, p. 170), a internet possui sua própria geografia: "Novas configurações territoriais emergem de processos simultâneos de concentração, descentralização e conexão espaciais, incessantemente elaborados pela geometria variável dos fluxos de informação global".

Ou seja, a partir de qualquer lugar geográfico um 
usuário poderá capturar um momento para registro e compartilhamento com demais usuários. Poderá esta imagem gerar interação com outros usuários, independentemente do que seja. Ela poderá passar uma sensação, pois como lembra Manovich, o Instagram não conta uma história, ele serve para outro uso, que o autor questiona durante seu texto, chamando o ato de publicar fotos no Instagram de Instagrammism:

O Instagrammism não se trata de "contar uma his tória", e não apresenta "sujeitos" apropriados (no sentido de "sujeito de uma foto"). [...] Não se trata de mostrar, significar, registrar, narrar ou convencer. E não se trata de transmitir um "sentimento" também, isso seria muito simplista. Realmente, qual é o "sentimento" expresso por uma visão de close-up de objetos texturizados dispostos sobre uma mesa, ou uma mão segurando um copo de cappuccino na luz da manhã? Você pode nomear esses "sentimentos"? E, finalmente, eles não são mesmo sobre "estilo". Pessoas bem vestidas e design de quartos de hotel têm "estilos"15 (Manovich, 2016, p. 10, tradução nossa).

Portanto, como é uma ferramenta livre (até o limite que sua administração permite) para publicação de imagens e vídeos, qualquer usuário poderá postar somente o que gostaria. Sabe-se que muitas publicações são puramente para fins comerciais. Porém, como mencionado na introdução, este artigo trata das imagens como memórias de algo, como por exemplo, um local, uma pessoa ou, simplesmente, um registro de algum detalhe do que aconteceu no momento.

\section{Características nativas da mobilidade presentes no Instagram}

Possivelmente alguns dos laços mais evidentes da ligação do Instagram com a mobilidade seja a categoria tempo. O prefixo Insta do Instagram justamente ilustra a questão da captação de informações em tempo real pelo usuário. Esta coleta de imagens representa um fluxo de registro e compartilhamento de realidades que o interagente busca promover com seus pares ou de forma pública. A mensagem característica desta rede é, portanto, vinculada necessariamente como presente. Usuários que colocam imagens oriundas de arquivos de tempos remotos causam um inicial estranhamento em sua comunidade de audiência. Estas imagens normalmente acompanham uma meta-texto em forma de legenda para evidenciar que se trata de um retrato do passado.

Tanto o fluxo da captura como o consequente compartilhamento de mensagens imagéticas são resultantes da simbiose com o hardware que o aplicativo Instagram possui. Este sistema precisa estar na forma de software e não de página da web justamente pela conexão umbilical entre os bits, sensores e processamento. $O$ módulo de câmera fotográfica captura a imagem que é processada com variações de filtros estéticos no módulo de $\mathrm{CPU}^{16} \mathrm{e}$ compartilhadas usando alguma variação de rede wireless local ou celular. Esta dinâmica de fluxos evidencia o fato desta rede ter se originado nativamente em ambiente móvel e não necessariamente derivada de um ambiente desktop como demonstra Henriques (2011).

Em Manovich (2002) já era possível entender que as dinâmicas intrínsecas na linguagem de informações digitais estavam imbricadas em formatos de software. Mas o mesmo software se transforma para dispositivos móveis e ganharam a popularidade na denominação de aplicativo, ou Apps ${ }^{17}$. A popularização de Apps como o Insta- gram é também resultante da evidente proliferação dos smartphones. O software se torna objeto do cotidiano e se torna ferramental para captura, armazenamento e compartilhamento de memórias e interações sociais.

\section{Elementos da interface gráfica do}

Instagram como conectores dos espaços físicos e virtuais

Nas últimas décadas, as redes sociais on-line vieram conquistando seu espaço, inicialmente entre usuários de computadores e posteriormente entres os usuários de smartphones. Estas redes sociais funcionam por detrás de uma interface gráfica de usuário (GUI) que, conforme Johnson, seriam "softwares que dão forma à interação entre usuário e computador. A interface atua como uma espécie de tradutor, mediando entre as duas partes, tornando uma sensível para a outra" (1997, p. 17). Portanto, as redes sociais online têm diversos recursos e funcionalidades em suas interfaces que as tornam intuitivas e compreendidas para seus usuários. Quanto aos sites redes sociais, Recuero os define como uma categoria do grupo de softwares sociais, que seriam softwares com aplicação direta para a comunicação mediada por computador (2009).

O Instagram é um software que surgiu posterior a esta definição, e sua diferença foi ter sido elaborado especificamente para o uso de smartphones, já em forma de aplicativo. Segundo Manovich (2016), ele surgiu trazendo elementos diferenciais de outros serviços de edição de foto, como o compartilhamento, além da possibilidade de edição e filtros, que o viralizariam em um universo de imagens bonitas e que conectariam pessoas e suas experiências. $\mathrm{O}$ Instagram permite a publicação de fotos editadas e tratadas pelo próprio usuário praticamente de forma instantânea. Ao postar uma 
foto, o usuário pode marcar algum local, além de outras pessoas, indicando onde e com quem esteve, para que seus amigos visualizem. O grande trunfo do aplicativo é o número de curtidas em suas fotos e visualizações em seus vídeos.

Em meados de 2016, o Instagram lançou novas funcionalidades, permitindo ao usuário a publicação de histórias $^{18}$, ou seja, publicação de fotos e vídeos curtos, nos quais se pode inserir emojis, textos, desenhos à mão livre ou figuras gráficas pré-estabelecidas. Também permitem o uso de outros recursos disponíveis no aparelho, como marcação de local, temperatura, e reconhecimento de uma face humana, disponível na câmera. Essas histórias podem ser configuradas para aparecerem a apenas alguns contatos, ao contrário das fotos na timeline, porém também recebem um feedback de visualizações e são passíveis de comentários. As histórias delimitam micromomentos do usuário, podendo ele narrar através de imagens diferentes fatos de seu cotidiano. Acredita-se aqui que as histórias, pelo fato de sua duração ser de apenas 24 horas, passam alguma ideia de presença do usuário.

Quanto às imagens publicadas, apesar de o aplicativo ser gratuito, não existe um limite de postagens e o usuário poderá postar quantas fotos quiser, a qualquer momento e onde estiver, desde que com alguma conexão com a internet. Tendo em vista esta questão, é trazida à tona uma ideia levantada por Lévy, que há quase duas décadas já comentava sobre o armazenamento, a noção de tempo, a condensação no presente e, por fim, de um tempo que se torna pontual.

A noção de tempo real, inventada pelos informatas, resume bem a característica principal, o espírito da informática: a condensação no presente, na ope- ração em andamento. $O$ conhecimento de tipo operacional fornecido pela informática está em tempo real. Ele estaria oposto, quanto a isto, aos estilos hermenêuticos e teóricos. Por analogia com o tempo circular da oralidade primária e o tempo linear das sociedades históricas, poderíamos falar de uma espécie de implosão cronológica, de um tempo pontual instaurado pelas redes de informática (Lévy, 1994, p. 115, grifos nossos).

Talvez, na época em que Lévy publicou sua ideia, o contexto tenha sido mais tecnicista, no sentido da informatização de dados. Porém, resgatando esta questão para o contexto de um aplicativo que desmaterializa equipamentos que antes eram imprescindíveis, resgatando momentos através de postagens de fotos, comentários em álbuns e timelines, temos o tempo pontual, ou um presente condensado por micromomentos, mesmo que de um determinado passado. Este micromomento condensado é realizado através de agrupamentos de fotos e seus elementos, podendo ser agrupados por hashtags e localizações delimitadas por inúmeros usuários de distintos lugares e culturas. Por outro lado, as histórias condensam o momento atual, por permanecerem apenas 24 horas no ar, permitindo uma visualização quase em tempo real da vida dos usuários seguidos. Diferente da timeline, estas histórias narram os últimos fatos de um usuário para seus seguidores.

Tanto nas postagens da timeline, quanto nas histórias, existe a conversação entre os usuários participantes, seja ela feita através das curtidas, ou através de comentários. Recuero (2012) aborda três elementos que possibilitam a construção de contextos na conver- sação online. Seriam eles: a) negociações entre os participantes; b) conversações podem ser assíncronas, ou continuadas em momentos diferentes; c) limitações e possibilitadas pelo design das ferramentas utilizadas. Ou seja, para que o contexto seja entendido, é preciso que a ferramenta disponibilize os recursos necessários e, no caso do Instagram, isso parece ser verdadeiro, pois existe a permanência da imagem publicada, quando no caso da timeline, junto à quantidade de tempo que passou desde que ela foi publicada, além de autor, possível local e possível presença de algum sujeito. Recuero comenta que

a negociação e a construção do contexto é uma parte importante da conversação como apropriação das ferramentas de CMC. Especialmente nas ferramentas assíncronas, o desenvolvimento do diálogo necessita de um contexto que seja provido de forma permanente e que esse contexto, portanto, possa ser recuperado (2012, p. 113).

Isto, no caso do Instagram, pode ser entendido pelo contexto da própria imagem, que também pode estar relacionada a alguma hashtag ou localização, além de uma legenda. Usuários que percorrerão a linha do tempo de outro usuário e verão a foto dias ou semanas após a sua publicação, a entenderão através do contexto que o autor da foto expôs - e sua negociação para quem a pudesse entender. Em outras palavras, uma foto publicada pode ser entendida por apenas um grupo de usuários seguidores, levando em conta a negociação estabelecida. Outro grupo poderá interagir, apesar de o contexto real da foto estar ocultado na publicação.

O Instagram, além das já citadas timeline e histórias, 
tem outra forma de publicação de fotos, que é o envio de posts para amigos específicos. Porém, neste texto, trataremos dos aspectos de fotos postadas para a rede de amigos e não sobre as fotos enviadas separadamente para uma pessoa ou um grupo. É através dela que outros usuários irão experimentar, através da imagem publicada e visualizada em tela de smartphone, uma sensação do momento, do local ou da experiência que o usuário autor postou. Interessante observar que as fotos do Instagram geralmente são trabalhadas de acordo com o que se deseja passar. Existem os diferentes filtros que possibilitam a melhoria ou edição de uma imagem para determinado fim, ou seja, se o usuário quer dar mais vida à foto (ou ao vídeo), poderá escolher filtros que realcem mais as cores, ou poderá querer dar um aspecto mais artístico, podendo optar por imagens em preto e branco, por exemplo. As fotos remeterão a alguma sensação ao usuário, seja ela mais próxima à realidade fotografada ou não. Isto novamente leva a um trecho da obra de Lévy (1994, p. 170), que trata da consciência que temos das coisas e da memória humana: "A consciência pode ser considerada como uma das interfaces entre o organismo, seu ambiente e o funcionamento de seu próprio sistema cognitivo. É o sistema de fixação de uma parte da memória de curto prazo, a pequena janela sobre os processos controlados".

Percebendo esta questão da memória no Instagram, o usuário tem consciência de como era o ambiente ou a situação cuja foto retratada está publicando. Porém, a memória exata do que foi vivido é de curto prazo e, ao passo que a publica, esta foto passa a ser uma memória, agora transformada através de filtros e, talvez, complementada pelas interações dos outros usuários naquela postagem. É criada assim, uma ideia de presença por parte dos interagentes na publicação. Rheingold (2003) comenta sobre uma conversa realizada com pesquisadores da empresa de tecnologia móvel Nokia, em que perguntava se a definição de presença se fazia incompleta quando fora do contexto físico e levado para um contexto virtual, em que a pessoa estava sozinha. De acordo com uma das pesquisadoras, enquanto os participantes estivessem trocando informações no grupo, eles seriam considerados como presentes. Assim, perceberam que, mesmo em encontros físicos, as pessoas seguiam usando um celular para se comunicarem virtualmente, ou seja, dando a ideia de que mais pessoas poderiam estar ali.

A memória remete também para a questão da assincronia, já apontada por Recuero (2012), das mensagens entre usuários de redes sociais. Qualquer pessoa conectada e que tenha acesso às publicações de determinado usuário poderá comentar, a qualquer momento, nas fotos, independentemente de quanto tempo houver passado. Negroponte aborda esta questão, dizendo que "nem todas as nossas comunicações precisam ser imediatas e em tempo real. Somos constantemente interrompidos ou obrigados a ser pontuais por coisas que, na verdade, não merecem tanto imediatismo ou presteza" (1995, p. 162).

Outra questão interessante de observar são os agrupamentos de locais através do recurso de marcação de local da ferramenta. Todas as imagens postadas contendo marcação de respectivo local aparecerão listadas (com exceção às de contas privadas) e exibidas abaixo de um mapa da localidade específica. Estas imagens conectam visões de diferentes usuários, permitindo a visualização de diferentes pontos de vista sobre uma mesma coisa. Um mesmo local será citado como ponto de passagem por milhares de pessoas que não se conhecem, deixando todo um rastro naquele ponto do espaço virtual. Faz-se um link com Santaella (2008, p. 98), que diz que "de fato, a tecnologia móvel nos força a reconsiderar o espaço, alegibilidade do espaço, o modo como as pessoas reencontram o espaço cotidiano, pois, quando o movimento da cidade e a mobilidade humana - ambos tecnologicamente mediados - se cruzam, múltiplas espacialidades podem se interseccionar".

Existem as telas de agrupamento de publicações por locais e hashtags. Percebe-se que pelo tamanho da tela de um aparelho celular, o número de imagens que aparecem é bastante reduzido. Ao visualizar uma timeline, o usuário vê apenas uma foto por usuário. Quando abre um perfil (conta de usuário que está seguindo), hashtag ou localização, existem opções que permitem ver um mosaico de imagens postadas para cada contexto. Cabe aqui uma frase de Santaella, que diz que "todo pensamento é indissociável da percepção e da ação" (2004, p. 151), trazendo à tona o fato de que tudo que vemos leva a alguma sensação de algo já conhecido por nós e que experimentaremos, ou seja, qualquer foto editada, ou não, e observada no Instagram, poderá remeter a alguma memória ou sensação, seja sobre o usuário, a localização ou o contexto da hashtag.

Isto nos leva a considerar que cada indivíduo terá sua maneira de agir e de usufruir determinado espaço, seja ele físico ou virtual. Goffman (1985) elaborou um estudo a respeito das faces que as pessoas usam em determinadas situações, como agir em público ou de forma privada. A partir disto, Rheingold (2003) menciona suas ideias sobre as diferentes faces representadas para diferentes audiências, em se tratando de espaços, que se moldariam conforme o ambiente ou a conversa, e o usuário decidiria conscientemente ou não qual a face usar em questão - se condizente ao ambiente físico em que se encontra ou ao assunto da conversa no telefone. 
Rheingold (2003) posteriormente comenta que as formas do comportamento coletivo possibilitado ou alterado, através das tecnologias que denomina smart mobs, vai além da etiqueta de onde e como utilizar o uso de celular"19. Segundo o pesquisador, "as mudanças mais radicais são àquelas em nível de sociedade ${ }^{20 \prime \prime}$ (Rheingold, 2003, p. 28). Levando em consideração a época em que este texto foi escrito e o tempo percorrido até então, percebe-se o quanto a sociedade contemporânea teve seu comportamento alterado devido ao uso de tecnologias como o celular, ou, mais recentemente, o smartphone. Falar em público requer algumas etiquetas, assim como registrar e publicar imagens também. No caso do Instagram, cuja interação ocorre em uma publicação específica ou mesmo com outro usuário, o comportamento dependerá também dos recursos que a interface disponibiliza para suas ações.

Tratando dos novos rumos que as novas tecnologias possibilitam, Negroponte argumenta que estamos entrando numa era da pós-informação, em que "os meios de comunicação de massa tornaramse simultaneamente maiores e menores" (1995, p. 157). Amplia-se a audiência, as formas de informar, porém para nichos específicos e não mais para uma massa. Quanto a questões de localização e de espaço, o pesquisador fez um comentário bastante certeiro - há mais de duas décadas, que "a vida digital exigirá cada vez menos que você esteja num determinado lugar em determinada hora, e a transmissão do próprio lugar vai começar a se tornar realidade" (Negroponte, 1995, p. 159). Ele segue com alguns exemplos que permitem uma reflexão de que ainda existem algumas lacunas a serem preenchidas para uma sensação mais real de estar presente num determinado espaço geográfico:
$\mathrm{Se}$, da janela eletrônica da minha sala de estar, eu pudesse de fato ver os Alpes, ouvir os cincerros e sentir o cheiro (digital) do estrume no verão, eu poderia, de certo modo, dizer que estou na Suíça. Se em vez de ir trabalhar levando meus átomos para o centro da cidade, eu acessar meu escritório e fizer meu serviço por via eletrônica, qual será meu local de trabalho? (Negroponte, 1995, p. 159).

\section{Considerações finais}

Este artigo fez um apanhado sobre aspectos da mobilidade, retenção de momentos e feedback através da ferramenta Instagram, além dos elementos da interface gráfica do usuário como conectores dos espaços físicos e virtuais. Por ser uma questão que está em emergência e ainda carece de estudos, foram observados alguns aspectos sobre este tipo de interação e, para tanto, abordaram-se autores que contribuíram com uma reflexão sobre cada um.

Inicialmente, percebeu-se que o espaço físico muitas vezes perde totalmente seu sentido, pois qualquer pessoa pode estar presente de forma virtual em lugares diferentes. Poderá visualizar imagens e sentir-se como se estivesse em algum espaço que já visitou. Isto, obviamente, é uma questão que as tecnologias de realidade virtual estão tratando de melhorar a cada novo produto lançado. Porém no caso deste trabalho, como estamos tratando de um aplicativo cujo uso é específico para celulares do tipo smartphone, ainda existem alguns limites. As imagens são visualizadas em tamanho da tela do aparelho do usuário, os vídeos têm duração limitada e, ao contrário do que Negroponte (1995) apontou, ainda não chegamos ao ponto de sentir o cheiro das coisas nem sentir sensações como vento, frio ou calor. Porém, sabe-se que as tecnologias para chegar a este ponto se- guem em desenvolvimento.

O que se tem aqui é a lembrança que pode ser transformada com os recursos da interface do Instagram. Uma foto de um animal de estimação ou de uma flor, vista em determinado contexto, passará por filtros e edições e se transformará, talvez, em outra coisa que não aquela visualizada ao vivo, no momento da imagem. Desta forma, o usuário terá uma memória do que vivenciou, e através do Instagram, uma memória - de certa forma - construída daquela situação. Poderá fazer um recorte de somente um detalhe, sem mostrar todo o contexto. Poderá dar mais ou menos luz e cor a uma situação que não era tão colorida, parecendo ser.

Um fato interessante de observar, em termos de quantidade e diversidade de fotos, diferente de épocas em que as fotografias eram impressas (ou reveladas) é que atualmente elas se mantêm agrupadas em ambientes virtuais, como nuvens. Diferentes usuários que marcam fotos de um mesmo local as colocam em uma coleção virtual daquele local. Isto pode ser feito por marcações, disponibilizadas na interface da ferramenta, como também através do uso de hashtags, que permitem agrupamentos por palavras-chave. Pensando assim, usuários das mais diferentes culturas e fotos de contextos bastante variados se misturam nestes agrupamentos, formando assim coleções que, de certa forma, contam uma história de locais e de coisas.

Outro ponto que vale ser considerado é a assincronia com que usuários podem interagir com estas fotos, independente do período em que a foto foi tirada. Como os recursos de curtir e comentar permanecem em todas as fotos publicadas, qualquer outro usuário conectado ao perfil do autor da publicação poderá, a qualquer momento posterior a esta, interagir. Ou seja, poderá curtir uma foto e dentro do campo de comen- 
tários escrever algo ou mesmo marcar outras pessoas. Percebe-se, também, a característica do Instagram de ser um espaço onde pessoas postam, em grande parte, conteúdos livres, mostrando desta maneira um histórico de imagens agrupadas por elementos como locais, usuários e hashtags. Assim, através das telas do Instagram, usuários encontram qualquer conteúdo, desde que liberado pelo usuário autor através de um perfil aberto. Podem experimentar, dentro dos limites permitidos pela ferramenta, a experiência que o usuário autor teve na hora de publicar determinado conteúdo. No caso de fotos de local, por exemplo, agrupadas por uma hashtag ou marcação de local, um usuário que esteja navegando e irá interagir, poderá também visualizar duas fotos de um mesmo local, porém editadas, criando um contexto extremamente diferente.

A interface gráfica do Instagram disponibiliza algumas funcionalidades, como marcar pessoas e locais em suas publicações. Para tanto, é necessário que a pessoa habilite o localizador de seu celular, e para marcar amigos, deverá ter algumas conexões já estabelecidas. É interessante observar que a função de curtir uma foto é possibilitada através de um ícone em forma de coração, que simboliza universalmente o amor. Ou seja, percebese que para curtir uma foto, entende-se que o usuário precisa gostar demais dela, levando em consideração o conteúdo e a edição feita por quem a publicou. Quanto às fotos, o Instagram inicialmente permitia somente postar fotos quadradas, obrigando o usuário a cortar suas imagens. Atualmente, já permite mais flexibilidade em formatos até 3:4. Os vídeos também passaram de cinco segundos para um minuto no decorrer destes seis primeiros anos. Somente até meados de 2016, o Instagram já contava com mais de 25 atualizações realizadas, entre melhorias e inserção de funcionalidades. Entre as mais recentes: a mudança de sua interface, dando mais ênfase às histórias (que passaram a aparecer fixas no topo da timeline, sempre que houver), a possibilidade de zoom nas fotos e vídeos mais longos (de até um minuto).

O Instagram não apresenta muitos recursos para interação de usuários em sua interface - se comparado a outras redes sociais, como o Facebook, por exemplo mas parece permitir mais que o usuário brinque e explore suas sensações ao momento de compartilhar uma foto de acordo com o que deseja que os seus seguidores percebam e compreendam. Ele faz uma negociação com seus seguidores neste momento, como diz Recuero (2012). Retomando, esta rede social nos evidencia que a comunicação móvel é caracterizada pela inserção no cotidiano. Os smartphones são interfaces para captura e armazenamento de informações que se transformam em uma espécie de meta-memória. A realidade é amplificada, editada e compartilhada neste contexto.

Apesar o presente artigo dar enfoque para o uso pessoal do Instagram, vale mencionar sua importância como ferramenta de marketing para empresas que promovem produtos e serviços através de publicações. Estas, de certa forma, posicionam-se dentro das timelines dos usuários comuns através de algoritmos, pois podem ser pagas para aparecerem a determinado perfil de público -usuário. O Instagram é uma mídia que pode ser muito bem trabalhada, levando em consideração seu público alvo de seguidores, devido à grande importância que a imagem tem como influenciadora para cada contexto de nicho de mercado. Não só para marcas já reconhecidas e famosas, o Instagram se tornou um grande aliado para blogueiras de moda, por exemplo, que utilizam a rede para a promoção de looks, roupas e acessórios, podendo mostrar sensações em contextos diferentes, além de permitir uma aproximação com o público desejado. Es- tes posts, diferentes dos citados no corpo do texto acima, são patrocinados, procurando atingir um público alvo bastante específico, porém tem grande eficácia e muitas vezes são compartilhados em timelines pessoais de usuários, levando o usuário a ser também um influenciador para seus seguidores, por partilhar imagens que para estes Ihes são também interessantes.

\section{Referências}

CASTELLS, Manuel. A Galáxia da Internet: Reflexões sobre a internet, os negócios e a sociedade. Rio de Janeiro: Jorge Zahar, 2003.

CASTELLS, Manuel, FERNÁNDEZ-ARDÈVOL, Mireia; QIU, Mireia; SEY; Araba. Mobile Communication and Society: A Global Perspective. Cambridge: MIT Press, 2007.

GILDER, George. Telecosm: How infinite Bandwith will Revolutionize Our World. Nova lorque: Free Press, 2000.

GOFFMAN, Ernst. A Representação do Eu na Vida Cotidiana. Petrópolis: Vozes, 1985.

HENRIQUES, Sandra Mara Garcia. O fator da mobilidade nas redes sociais e tecnologias de comunicação: um estudo sobre as potencialidades da plataforma locast. Dissertação (Mestrado em Comunicação Social). Faculdade de Comunicação Social, Pontifícia Universidade Católica do Rio Grande do Sul, Porto Alegre, 2011.

JOHNSON, Steve. Cultura da Interface: Como o computador transforma nossa maneira de criar e co- 
municar. Rio de Janeiro: Jorge Zahar, 1997.

LEMOS, André. Cultura da Mobilidade. Revista Famecos, Porto Alegre, v.1, n.40, p. 28-35, 2009.

LÉVY, Pierre. Tecnologias da inteligência. São Paulo: $34,1994$.

MANOVICH, Lev. Software takes command. Nova lorque: Bloomsbury, 2013.

Notes on Instagrammism and mechanisms of contemporary cultural identity. Manovich, 2016. Disponível em: <http://manovich.net/index.php/ projects/notes-on-instagrammism-and-mechanisms -of-contemporary-cultural-identity $>$. Acesso em: 10 jan. 2017.

The language of new media. Cambridge: MIT Press, 2002.

MANOVICH, Lev.; DOUGLASS, Jeremy.; ZEPEL, Tara. How to compare one million images?. Software Studies Initiative, 2011. Disponível em: <http://softwarestudies.com/cultural_analytics/2011.How_To_ Compare_One_Million_Images.pdf $>$. Acesso em: 10 jan. 2017.

NEGROPONTE, Nicholas. Vida Digital. São Paulo: Companhia das Letras, 1995.

PELLANDA, Eduardo Campos. Internet Móvel: novas relações na cibercultura derivadas da mobilidade na comunicação. 2005. Tese (Doutorado em Comunicação Social). Faculdade de Comunicação Social, PU-
CRS, Porto Alegre, 2005.

PERAICA, Ana. Culture of the Selfie: Self-Representation in Contemporary Visual Culture. Amsterdã: Institute of Network Cultures, 2017.

RAI, Saritha. India just crossed 1 billion mobile subscribers milestone and the excitement's just begining. Forbes, 06 jan. 2016. Disponível em: <http://onforb.es/22KgmgG>. Acesso em: 06 jan. 2017.

RECUERO, Raquel. Redes Sociais na Internet. Porto Alegre: Sulina, 2009.

A conversação em Rede: Comunicação Mediada pelo Computador e Redes Sociais na Internet. Porto Alegre: Sulina, 2012.

RHEINGOLD, Howard. Smart Mobs. Cambridge: Perseus Publishing, 2003.

SANTAELLA, Lúcia. Navegar no ciberespaço: o perfil cognitivo do leitor imersivo, São Paulo: Paulus, 2004.

Mídias locativas: a internet móvel de luga-

res e coisas. Revista Famecos Porto Alegre, v.1, n. 35, p. 95-101, 2008.

STATISTA. Number of mobile phones users worldwide from 2013 to 2019 (in billions). Disponível em: <http://goo.gl/1OsVu7>. Acesso em: 06 jan. 2017.

Notas

1 Trabalho apresentado no XXXIX Congresso Brasileiro de Ciências da Comunicação.
2 Doutor em Comunicação Social pela Pontifícia Universidade Católica do Rio Grande do Sul. Pós-Doutoramento pelo Massachusetts Institute of Technology (MIT). Professor do Programa de Pós-Graduação em Comunicação da PUCRS. Coordenador do Laboratório de pesquisa em mobilidade e convergência midiática (UBILAB). (Av. Ipiranga, 6681, Partenon, CEP:90619-900 - Porto Alegre, RS - Brasil). E-mail: eduardo.pellanda@ pucrs.br.

3 Doutoranda do Programa de Pós Graduação em Comunicação da PUCRS (Av. Ipiranga, 6681, Partenon, CEP: 90619-900 - Porto Alegre, RS - Brasil). E-mail: mstreck@gmail.com.

4 Disponível em: <http://onforb.es/22KgmgG>. Acesso em: 06 jan. 2017.

5 Disponível em: <http://goo.gl/1OsVu7>. Acesso em: 06 jan. 2017.

6 Disponível em: <instagram.com>. Acesso em: 06 jan. 2017.

7 Em maio de 2016 o ícone do Instagram teve seu design alterado; a imagem que ilustrava uma câmera Polaroid foi transformada em um símbolo que remete à mesma, porém de forma simplificada.

8 "Soon your cellphone will be more powerful than your conventional PC. (...) It will take pictures and project them onto a wall or screen, or dispatch them to any other teleputer".

9 "Still they had an intention of sending a visual message to someone not present, a message reminder 
in the future. When seen by the intended addressee, these images provoked memories".

100 aplicativo foi criado em 2010, disponibilizado somente para iOS inicialmente. Em 2012 foi incorporado ao sistema Android e em 2013 no Windows Phone.

11 Emojis em japonês é a junção dos termos palavra com letra, e são ideogramas utilizados em mensagens eletrônicas ou comentários de redes sociais online.

12 Identificada pelo caractere \# antes da palavra-chave, e se torna um link que direciona a uma página que lista todo conteúdo que contenha a palavra-chave em questão.

13 Photoshop: Software para tratamento de imagens.

14 "Like these filters, many of the "new" techniques for media creation, editing, and analysis implemented in software applications were not developed specifically to work with media data. Rather, they were created for signal and information processing in general-and then were either directly carried over to, or adapted to work with media".

15 "Instagrammism does not care about "telling a story," and it does not feature proper "subjects" (in the sense of "subject of a photo"). (...) They are not about showing, or signifying, or registering, or narrating, or convincing. And they are not about conveying a "feeling" either, this would be too simplistic. Really, what is the "feeling" expressed by a close-up view of textured objects arranged on a table, or a hand holding a cappuccino cup in morning light? Can you name these "feelings"? And finally, they are not even about "style." Well-dressed people and design hotel rooms do have "styles".

16 CPU - Central Processing Unit.

17 Abreviação usada para o termo aplicação móvel.

18 Imita a tendência do Snapchat, app de rede social digital em que usuários publicam vídeos ou fotos que não permanecem - são automaticamente excluídos em até $24 \mathrm{~h}$.

$19 \mathrm{Na}$ época em que escreveu Smart Mobs, 2003, os aparelhos celulares eram utilizados para conversação através de ligações ou envio de mensagens de texto. Porém, entende-se para fins deste artigo, o uso do aparelho celular como um todo, atualmente permitindo diversas outras funcionalidades, dentre elas a captura e publicação de fotos através de aplicativos.

20 "the most radical changes are those possible at the level of entire societies". 